\title{
OS ÁRABES NOS ANTIGOS RELATOS PORTUGUESES DO ÍNDICO
}

\author{
ANTÓNIO DiAS FARINHA ${ }^{1}$
}

\begin{abstract}
Resumo - A Expansão árabe-islâmica alargou-se rapidamente na Ásia, África e Europa. Arabizou e islamizou muitos povos, conforme as circunstâncias, que foram designados genericamente por Mouros. A chegada dos Portugueses ao Oriente exigiu uma nomenclatura mais específica para designar a população da Arábia ou arabizada: Árabes, Alarves, Arábios, Beduínos, Maçaris e mesmo o nome de tribos como Ben Jebra [Banû Djabr].
\end{abstract}

Palavras-chave: Árabes, Muçulmanos, descobrimentos portugueses, história da expansão, Oceano Índico.

Abstract - ARABS IN OLd Portuguese accounts of the Indian Ocean. AraboIslamic expansion quickly spread throughout Asia, Africa and Europe and in certain circumstances led to the conversion to Islam of many people that were generically labelled Moors. The arrival of the Portuguese in the East called for a more specific way in which to refer to the population coming from Arabia or that which underwent the process of Arabisation: Arabs, Alarves, Arabians, Bedouins, Maçaris and even names of tribes like Ben Jebra [Banû Djabr].

Key words: Arabs, Muslims, Portuguese discoveries, history of expansion, Indian Ocean.

Résumé - LES ARABES, SELON LES ANCIENNES CHRONIQUES PORTUGAISES CONCERNANT L'OCÉAN INDIEN. L'expansion arabo-musulmane pénétra rapidement l'Asie, l'Afrique et l'Europe. Selon les circonstances, de nombreux peuples furent islamisés ou arabisés et furent alors appelés Maures. Mais l'arrivée des Portugais en Orient obligea à utiliser une nomenclature plus différenciée, distinguant les peuples de l'Arabie des peuples arabisés: Árabes, Alarves, Arábios, Beduínos, Maçaris, ou même à utiliser des noms de tribus, comme Ben Jebra [Banû Djabr].

Mots-clés: Arabes, Musulmans, découvertes portugaises, histoire de l'expansion, Océan Indien.

1 Professor Catedrático do Departamento de História da Faculdade de Letras da Universidade de Lisboa. 
Os primeiros contactos entre a população que vivia no ocidente da Península Ibérica e os povos islâmicos ocorreram quando da Expansão árabe-muçulmana que atingiu a Europa no alvor do século VIII (711). Desde essa data, a resistência cristã manteve algum território no norte peninsular e uma permanente vontade de Reconquista do solo ibérico.

A presença de comunidades de fé diferente não originou, nos primeiros séculos, uma dicotomia grave entre elas. Os conflitos surgiram mais de uma disputa pelo poder político-administrativo e militar do que pela vontade de impor uma crença religiosa. Durante muito tempo, mouros aliaram-se a cristãos contra outros mouros e a mesma indiferença de credo imperava quando algum grupo cristão tentava impor-se a outro.

Ao longo dos séculos, os mouros desenvolveram uma brilhante civilização no al-Ândalus, nome de baptismo do território ibérico sob dominação muçulmana, a partir de elementos orientais, africanos e peninsulares. Os reinos cristãos a norte procuravam assumir o padrão cultural romano, afeiçoado pelo Cristianismo, e que triunfava na Europa daquela época. As peregrinações a Sant'Iago de Compostela foram decisivas na ligação à Domus Dei, tal como a organização eclesial, em particular das Ordens Religiosas, como as de Cluny e de Cister.

A designação mais frequente adoptada pelos cristãos para referirem os invasores que atravessaram o estreito de Gibraltar para se instalarem na Ibéria foi a de Mouros, palavra já usada no tempo de Roma para a população do norte de África. Como essa população se convertera ao Islamismo e constituía a grande maioria da gente que emigrava, manu militari, para a Europa, aquele nome foi, naturalmente, adoptado para designar os invasores islamizados mas ainda não arabizados. Os homens originários da Arábia ou das regiões circunvizinhas que já falavam dialectos árabes, ou ainda aqueles já familiarizados com o idioma do Profeta que vieram para aquém de Gibraltar, apesar de dominarem o aparelho político, militar e administrativo e as funções ligadas ao culto e às actividades sufragâneas, permaneceram uma minoria em relação ao conjunto da população do al-Ândalus. Esse facto explica a razão pela qual se não escolheu o nome do povo no seio do qual surgira a nova religião, e da língua em que se tinha de recitar o Alcorão, para identificar os novos ocupantes do solo ibérico. Os muçulmanos sabiam, no entanto, que sendo aquele Texto o conjunto dos ensinamentos de Deus, não podia ser recitado noutra língua a não ser a original.

Devido à importância da organização tribal desde a época pré-islâmica até à época moderna (e mesmo até hoje) entre os árabes, surgia, frequentemente, uma indicação das tribos a que pertencia tal homem ou tal grupo, sem referência ao nome genérico de árabes.

Desde o início do século XIII, acentuou-se a clivagem entre as comunidades cristãs e muçulmanas, pelo que aumentou a tendência do uso do nome «Mouros» para designar os crentes na Fé que se pretendia ostracizar, pelo menos no que dizia respeito ao aparelho político e militar. Neste sentido, obliterou-se a noção de que os Mouros eram os habitantes do norte de África para o nome servir de 
identificação daqueles que adoptavam a crença de que «não há outra divindade a não ser Deus (Allâh) e Maomé (então dito correntemente «Mafamede», de Muhammad) o seu Profeta».

A situação alterou-se quando da Expansão portuguesa para o norte de África e para o Oriente. A imensidão do espaço geográfico, a variedade de povos, a complexidade das situações sócio-políticas, a distribuição assimétrica dos produtos de valor mercantil e a multiplicidade de crenças e costumes originaram um quadro complexo, perante o qual a escassez de recursos humanos e económicos dos portugueses, sempre a lidar com situações distintas, obrigou a um conhecimento mais profundo das comunidades e uma destrinça aperfeiçoada das suas características.

Em Marrocos os portugueses distinguiram claramente os «alarves» dos «bárbaros», os dois grupos mais numerosos do país. Todos estavam islamizados mas, enquanto os "alarves», plural de uma palavra derivada de al-'arab, designavam aqueles que já falavam árabe e assumiam essa identidade cultural, os «bárbaros» continuavam a falar as línguas e os dialectos berberes e só gradualmente adoptavam expressões e comportamentos de raiz árabe, em particular nos actos litúrgicos e nas palavras ligadas à crença religiosa. Essa distinção continua nos nossos dias, porque quase metade da população ainda tem o berbere como língua materna, apesar da arabização se ter acentuado devido aos programas escolares e ao império dos meios de comunicação modernos.

No final do século XV, o conhecimento do Oriente era vasto na Europa e mesmo em Portugal. As peregrinações dos muçulmanos que viviam no ocidente africano e ibérico a Meca e de cristãos a Jerusalém nunca foram interrompidas completamente. Relatos como os de Egéria ${ }^{2}$ (século IV) tornavam-se conhecidos nos meios religiosos e nas diferentes cortes da Europa. As cruzadas do século XI mantiveram estreitos contactos com variadas terras e gentes do Oriente. Impõe-se acentuar que, durante esse período, não houve só guerras. Depois dos embates armados, seguiam-se períodos em que a própria necessidade de subsistência induzia ao comércio, às trocas de produtos e mesmo à cumplicidade mercantil. Não se podem obliterar as numerosas dissensões que perduravam entre os grupos de muçulmanos, como nos reinos cristãos. Muitas vezes as rivalidades entre os naturais de diferentes países, alguns conflitos ou interesses opostos, sobrepujavam-se às identidades de crença. Estas não eram unívocas: além das heresias e seitas em cada religião, permaneciam, tal como sucede hoje, numerosos crentes da outra religião no campo adversário. Em todo o Médio Oriente havia (e há) um número expressivo de cristãos no seio de uma maioria de fiéis muçulmanos ${ }^{3}$.

2 Egéria. Viagem do Ocidente à Terra Santa, no Séc. IV. (Itinerarium ad loca sancta). Ed. Alexandra B. Mariano e Aires A. Nascimento. Lisboa: Edições Colibri, 1998.

3 O Diário da viagem de Vasco da Gama foi muitas vezes publicado; cf. a edição crítica de José Pedro Machado, Vasco da Gama e a sua viagem de descobrimento, Lisboa, 1969, p. 138. 
No final da Idade Média, os contactos com o Oriente aumentaram de maneira significativa com as viagens dos monges franciscanos e dominicanos e com as iniciativas de mercadores como os Pólo, tendo sido o relato de Marco Pólo amplamente divulgado.

A empresa portuguesa do Oriente foi preparada a partir de um conhecimento relativamente correcto das realidades do Oriente e de uma recolha pormenorizada de informações, em particular daquelas que provinham do Oriente próximo. A própria titulatura adoptada por D. Manuel em 1499, após o regresso de Vasco da Gama, denuncia não só o plano manuelino, mas também o quadro geográfico de que havia suficiente conhecimento: «senhor da conquista, navegação e comércio de Etiópia, Arábia, Pérsia e Índia». Apesar de tão vasto propósito, não existe qualquer referência nem à Insulíndia, nem à China (Cataio), nem ao Japão (Cipango).

O primeiro português que documentalmente sabemos que esteve no Oriente, em especial na região da Arábia, foi Pêro da Covilhã que, por duas vezes, passou pelo Mar Roxo, Golfo Pérsico e Mar da Arábia em rota para Calecute e Sofala. Não conhecemos o relatório que terá enviado a D. João II antes de se dirigir à Abissínia onde ficou até ao seu passamento. Dessa forma, as primeiras referências feitas por portugueses às populações da zona do oceano Índico foram escritas no diário da viagem de Vasco da Gama (1497-1499), atribuído a Álvaro Velho.

A bordo dos navios que, em 8 de Julho de 1497, zarparam de Lisboa rumo à Índia iam homens experimentados nas coisas do mar, mas também conhecedores das línguas e costumes dos muçulmanos, em particular do idioma arábico. Habituados a contactar diferentes povos, exigia-se-lhes a identificação dos seguidores do Profeta, geralmente inimigos desde os conflitos do período das Cruzadas e das guerras que não mais cessaram. Tratava-se de uma indagação recorrente. Na costa da África ocidental, ao escreverem sobre os povos primitivos da zona da Guiné, os autores não se esqueciam de anotar se eram «fanados» ou não, para assim averiguar se a cicatriz da circuncisão denunciava a penetração do credo islâmico. Por outro lado, o conjunto das práticas muçulmanas como o das orações, dos interditos alimentares, a escolha dos nomes próprios, os hábitos de higiene que exigiam as abluções rituais, o tipo de vestuário e muitos outros sinais e comportamentos que de forma tão acentuada caracterizam o homem muçulmano em qualquer paragem, não permitiam aos nautas portugueses qualquer tipo de dúvida ou de hesitação perante interlocutores islamizados.

Nos primeiros contactos na costa oriental de África, os portugueses ouviram os muçulmanos designar os negros não convertidos por «cafres», palavra derivada do árabe «kâfir», que significa «infiel», «não crente». Essa designação originou o nome «terra dos cafres» ou "cafraria», com que ficou desde logo conhecida a terra que de Moçambique se estendia para as regiões meridionais de África. A esses habitantes, de civilização ainda rudimentar, objecto da 
nova designação, assacou-se-lhes o epíteto de pouco desenvolvidos, ou «selvagens», sofrendo aquele nome uma depreciação evidente.

Os portugueses não só reconheciam os muçulmanos, mas também algumas das suas qualidades ou preeminências. Assim, identificaram alguns xarifes que viviam na costa oriental de África. A palavra «xarife» significa «nobre, de estirpe elevada» e aplicou-se, no mundo islâmico, aos descendentes da família do Profeta. Com tal abonação, não admira que tenham surgido numerosos ramos de xarifes que entroncam a sua origem em Maomé e seus familiares. São muito venerados entre os muçulmanos, por se considerar que são portadores da «bâraka» ou bênção divina.

Os habitantes das várias províncias da Arábia, em particular das regiões hoje ocupadas pelo sultanato de Oman e pelo Iémen, os oriundos das zonas costeiras da África, da Somália ao Egipto e, ainda, do litoral da Pérsia enxameavam o oceano Índico e, nas costas de Moçambique e da Tanzânia actuais, buscavam o ouro do Monomotapa, escravos negros, marfim e outros produtos tropicais. Como, desde o século XI, se tinham desenvolvido formas de misticismo muçulmano com a formação de confrarias sufis, foi por essa via que se acentuou a islamização da franja litoral da população negra, cujos membros serviam, frequentemente, de agentes comerciais aos numerosos mercadores árabes.

A Expansão árabe-muçulmana atingira toda a área do Índico, particularmente os locais portuários favoráveis aos negócios e que na nomenclatura histórica de língua inglesa são designados por «ports of trade». Era o que acontecia na zona do Gujarate, em todo o litoral Índico e da Insulíndia. Na costa do Kerala distinguiam-se bem os "mouros da terra» e os "mouros de Meca», tal como foram designados pelos portugueses. Os primeiros, os Mappila, tinham escolhido permanecer naqueles lugares, casaram com mulheres nativas, ganharam descendência e serviam de intermediários entre os antigos habitantes da terra e os mercadores e os «mouros de Meca» que demandavam aqueles portos nas épocas favoráveis da monção. Os últimos, os Pardexi, não se haviam fixado e viajavam entre os diferentes portos do Índico, mar Vermelho e golfo Pérsico. Estes só por acaso eram naturais da cidade de Meca; na verdade, eram oriundos da península Arábica e das regiões limítrofes.

Logo que a armada de Vasco da Gama atingiu a ilha de Moçambique, o autor do Diário escreveu:

"Os homens desta terra sam ruyvos e de boons corpos e da seita de Mafamede e falam como mouros, e as suas vestiduras sam de panos de linho e d'algodam muito delgados e de muitas cores, de listras, e sam ricos e lavrados. E todos trazem toucas nas cabeças com vivos de seda lavrados com fio d'ouro, e sam mercadores e tratam com mouros brancos, dos quaees estavam aquy em este logar quatro navios delles [...]»

"E isso tudo entendia huum marinheiro que o capitam moor levava, o qual fora já cativo de mouros e, portanto, entendia estes que aquy achamos». 
«E mais diseram os ditos mouros que aviamos que, neste caminho que levavamos [...] aviamos de ir topar com hũa ilha em que estava a metade mouros e a metade christãoos, os quaees christãoos tinham guerra com os mouros» 4 .

Noutra passagem, o mesmo autor escreve que «o rey de Monçobiquy que queria fazer paz comnosco e ser nosso amigo e desta paz foy embaxador huum mouro branco que era xarife, que quer dizer crelego [clérigo], o quall era huum grande bebado. E em estando nos aquy veo huum mouro [...]» ${ }^{5}$.

As observações do atento autor do Diário sucedem-se, sobretudo no que respeita à distinção entre os muçulmanos e os cristãos, ou a quem se atribuiu apressadamente essa qualidade. No entanto, a distinção é nítida entre o «mouro» e aquele que não o é. A seguir, atente-se noutro passo:

«E fomos em os bates a ver se podiamos tomar alguns delles [mouros] pera por elles avermos os dous christãoos ymdios que tinham cativos e o negro que nos alii fugira, pello quall fomos depos h_a almadia do xarife que hia carregada de fato $[\ldots] »$

«E nas almadias achamos muitos panos d'algodam finos e seiras de palma e hũa talha vidrada de manteiga e arredomas de vidraço com augoas e livros de sua Ley e huum cofe $^{6} \mathrm{com}$ muytas meadas d'algodam e hũa rede isso mesmo d'algodam e muitos seirões cheos de milho. E todas estas coussas que se alii tomaram o Capitam moor as deu aaquelles marinheiros que se alii acharam com elle e com os outros capitaeens, salvo os livros que elle guardou para mostrar a ell Rey» ${ }^{7}$.

Anote-se, finalmente, que o piloto que o rei de Melinde deu a Vasco da Gama para o levar à Índia, a quem Gabriel Ferrand, apressadamente, atribuiu uma identidade árabe, a do célebre piloto Ahmad Ibn Mâjid, surge no Diário como não muçulmano:

«Ao dia de Páscoa [15 de Abril de 1498] nos diseram estes mouros que tinhamos cativos que em a dita villa de Milindes estavam quatro navios de christãos, os quaees eram indios e que, se os quisesemos alii levar, que dariam por sy pilotos christãoos e todo o que nos fezese mester $[. .$.$] ” { }^{8}$.

4 O Diário da viagem de Vasco da Gama foi muitas vezes publicado; cf. a edição crítica de José Pedro Machado, Vasco da Gama e a sua viagem de descobrimento, Lisboa, 1969, p. 138.

5 Idem, ibidem, pág. 144.

6 A palavra «cofe», que se lê distintamente no manuscrito, foi transcrita, erradamente, por «cofre» em quase todas as edições do Diário. José Pedro Machado leu correctamente, indicou a etimologia certa, mas não deu o seu significado em árabe, nem a palavra portuguesa dela derivada. Ora cofe deriva de quffa e significa o mesmo que o português "alcofa» por ser o seu étimo. Aliás, o sentido do texto é muito claro e só por lapso a origem e o significado da palavra ainda não tinha sido esclarecido.

7 Idem, ibidem, pág. 146 .

8 Idem, ibidem, pág. 156. 
Compare-se esse texto com a passagem seguinte:

«Aquy achamos quatro naoos de christãoos da Imdia, os quaees, a primeira vez que vieram ao navio de Paullo da Gama, onde o Capitam moor estava, alii lhe mostraram huum retavollo em que estava Nossa Senhora com Jhesu Christo nos braços, ao pee da Cruz, e os Apostollos. E os indios, quando viram este retavollo, lançavam-se no cham, os quaees enquanto aquy estevemos, vinham fazer suas orações [...]»

«Estes imdios sam homens baços e trazem poucas roupas e trazem grandes barbas e os cabellos da cabeça muito longos e traze[m]-nos trançados e nam comem carne de boy, segundo elles diziam. E a sua linguajem he estremada da dos mouros e alguns delles sabem algũa pouca d'arravia [língua árabe] polla continoa comunicaçam que tem com elles» ${ }^{9}$.

O extraordinário cuidado com que era feita a destrinça da identidade entre o mouro e aquele que não o era não deixa dúvidas sobre a qualidade do piloto fornecido a Vasco da Gama pelo rei de Melinde. Acrescente-se que este piloto acompanhou a armada até Calecute e seria muito estranho se, durante todo esse tempo, permanecesse o embuste da verdadeira crença do piloto, até porque não se vislumbra qual seria o seu objectivo. O piloto guiou correctamente a frota do Gama até Calecute ${ }^{10}$. O autor do Diário é peremptório ao referir-se-lhe:

«E como foy o recado, el-Rey lhe mandou loguo huum piloto christão e o Capitam leixou logo ir aquelle fidalguo que elle tinha reteudo no navio. E folgamos muito com o pilloto christão que nos el-Rey mandou» ${ }^{11}$.

Quando os Portugueses em 1502 se dirigiram à Índia, na segunda viagem de Vasco da Gama, levavam na armada, em muitos exemplares, a edição de Marco Polo, em tradução portuguesa. Era um autêntico vade mecum para os viajantes. A edição ostenta o seguinte cólofon:

«Acabase ho livro de Marco Paulo. com ho livro de Nicolao veneto ou veneziano, e assi mesmo o trallado de hũa carta de huum genoves mercador que todos escreverom das Índias, a serviço de Deos e avisamento daquelles que agora vam pera as ditas Indias. Aos quaes rogo e peço humilmente que benignamente queiram emendar e correger ho que menos acharem no escrever, s. nos vocabulos das províncias, regnos, cidades, ylhas e outras cousas muytas, e nom menos em a distancia das legoas de hũa terra pera outra. Imprimido per Valentym Fernandez alemaão. Em a muy nobre cidade de Lyxboa. Era de mil e quinhentos e dous annos. Aos quatro dias do mes de Fevreyro» 12.

9 Idem, ibidem, pág. 160.

10 A maioria dos autores já não identifica o piloto de Vasco da Gama com Ahmad Ibn Mâjid; cf. Ibrahim Khoury, As-Sufaliyya «The poem of Sofala» by Ahmad Ibn Mâjid. Coimbra, Junta de Investigações Científicas do Ultramar, 1983.

11 Diário, ob. cit., pág. 162.

12 O livro de Marco Paulo. O livro de Nicolao Veneto. Carta de Jerónimo de Santo Estevam. Introdução de F. M. Esteves Pereira. Lisboa: Biblioteca Nacional, 1922, fl. 98v. 
Valentim Fernandes escreveu uma introdução, onde definia os termos «da província de Arabia atee onde se estende, e quantas som as Arabias»:

«A Arabia em geeral por arabigo he chamada Arab. E aquella que he antre ho mar Roxo e ho mar Persico elles chamam Gesirdelarab que quer dizer ylha da Arabia [...]»

Porem melhor he repartida a Arabia felix segundo os cosmografos Aravigos, os quaes a repartem em duas partes s. hũa que he interior, esta he aquella que vaa ter alem de Mecha pera riba atee seu cabo. E aquella propriamente he chamada a Arabia felix e do melhor encenso que quer dizer a provincia de Olibano. A qual em a nossa Escriptura he chamada Sabea, onde foy a Raynha de Saba. E esta tem diversos povoos e diversas heregias da secta de Mafomede, que antre sy tem repartida esta terra. E toda a outra parte desta terra s. da Arabia felix he chamada Hagees. Em esta he ho porto de Gyda [Jiddah] em que se descarregua a mercadoria de India e he do Soldam, e assim mesmo o porto de Mecha. E nom muy longe de Sabea no mar alto contra ho meo dia jaz a ylha chamada Secutera, onde nace ho ligno aloe secutrino. E he povoada de christaãos» ${ }^{13}$.

Deve-se ao famoso boticário Tomé Pires a mais antiga descrição das terras visitadas pelos Portugueses na zona da Península Arábica. Embarcou para a Índia em 1511 e escreveu o seu texto entre 1512 e 1515 . Nele relata a frustrada conquista de Adém em 1513 por Afonso de Albuquerque, mas parece ter concluído a obra antes da morte deste governador.

Ao descrever a Arábia, afirma Tomé Pires que:

«Tem este maar tres nomees: maar Roxo, mar Arabiquo, estreito de Mequa. Mar Roxo porque demtro no cabo junto com Çuez sam as barreiras vermelhas; maar Arabiquo porque jaz cerquado dos arabios; estreito de Mequa porque demtro nele jaz Mequa, casa de romaria dos mouros donde foy naturall seu Mafamede, mas o mais propiio nome he arabiquo» ${ }^{14}$.

Ao descrever o Egipto, Tomé Pires informa que «chaman-se os do Regno nestas partes maçariis». Esta palavra é a transcrição de misriy ou masriy, que significa «egípcio», derivada de Misr ou Masr, «Egipto» ${ }^{15}$.

No território ao norte da península arábica viviam muitos cristãos. Tomé Pires descreveu essa população:

«Ha nesta provimcia [Suez] e asy nos arabios muitos christãos deles circuncidados e deles nãao. Os circuncidados chamam-se Jacobitos, os outros

13 Ibidem, fl. Av, r.

14 A Suma Oriental de Tomé Pires. Leitura e notas de Armando Cortesão. Coimbra: Acta Universitatis Conimbrigensis, 1978, pág. 136-137.

15 Ibidem, pág. 138. Armando Cortesão ao tentar identificar a origem da palavra, desvalorizou o som ç (com cedilha), e sugeriu serem os habitantes do reino de Mekran, junto da foz do rio Indo. 
Malaquitos, tem duas cooresmas hũa em Natall \& outra a nosa. Nom casam hos huuns com os outros \& muitos deles sam irmitaees \& de samta vida \& deles homees de fazemdas \& sam muytos. Há destes em Juda [Jiddah], no Toro e em Meca, sam amtre estas gemtes ávidos por boos homees» ${ }^{16}$.

O etnónimo «alarves» é reservado aos nómadas. Tomé Pires refere que as mercadorias que partem do Cairo «vem em cáfilas com muita gemte d'armas, vem ao Toro, mas nem he ysto muitas vezes por causa dos salteadores alarves» ${ }^{17}$. A palavra é repetida em várias passagens com significado semelhante. Em Adem «som alarves» (p. 144). E, na região meridional da Arábia, repete que: «Despois d'Adem he Fartaque, as ilhas de Curia Muria e a Maseira, tudo ysto sam alarves, gemte de trato e boa gemte de peleja» ${ }^{18}$.

Do território ao sul, na Arábia Pétrea, afirma que «tem alarves ladroees, nom tem arvores, nem fruitos, nem augoa geerallmemte salvo em lugares dos alarves sabidos, sam ladroees nam tem outra vida, gemte maliciosa, fora de rezam, em cabilas amdam salteamdo omde ho acham» ${ }^{19}$.

Duarte Barbosa esteve vários anos na Índia e quando regressou a Lisboa, em 1516, compôs o livro que leva o seu nome. Nele distingue bem os habitantes do sudeste da península Arábica:

«Para o sertão de todos os lugares vivem mouros alarves, e são governados por xeques que os mandam e governam e às vezes vêem sobre estes lugares de Ormuz e lhes fazem guerra» 20 .

A cidade de Baçorá «em a qual sae da terra firme ao mar grande rio d'agua doce, o qual os mouros arabios e persios chamam Frata [Eufrates] [...] As gentes dela sam todos arabios» ${ }^{21}$.

Quanto à cidade de Ormuz, afirma que «os desta ilha e cidade são persios e arabios e falam arabia e outra lingoa que chamam persio» ${ }^{22}$.

Os nomes atribuídos a estes povos fixam-se quase imediatamente após a chegada dos Portugueses àquelas paragens. A palavra «alarves» é o nome colectivo das tribos nómadas que habitam as regiões desérticas e que devem deslocar-se para procurar alimento ou para transportar eventuais mercadorias.

O termo «arábio» foi formado a partir do étimo 'arabiyy, «aquele que é árabe, que tem a qualidade de árabe». A evolução da palavra foi semelhante à

6 Ibidem, págs. 140-141.

7 Ibidem, págs. 141.

18 Ibidem, págs. 147.

19 Ibidem, págs. 148

20 O Livro de Duarte Barbosa (edição crítica e anotada), vol. I, por Maria Augusta da Veiga e Sousa, Lisboa, IICT, 1996, pág. 133.

21 Idem, págs. 141-142.

22 Idem, pág. 151. 
de «algarvio», derivada de al-garbiyy «aquele que é do ocidente, ou natural do Algarve».

O conhecimento das terras e gentes do Oriente foi, desde o início da presença portuguesa, muito completo e aperfeiçoado ao longo dos anos. Autores como D. João de Castro, no Roteiro do Mar Roxo, escrito durante a expedição de D. Estêvão da Gama em $1541^{23}$, ou João de Barros, que publicou a Década I da Ásia em 1552, vieram confirmar as primeiras referências e introduzir algumas pequenas alterações na nomenclatura habitual. Ambos os autores se referem aos beduínos, nome dado às tribos nómadas de alguns lugares da Arábia. Alguns habitantes do território vizinho das ilhas de Curia Muria tentaram, em 1503, salvar Vicente Sodré, chefe da armada de vigilância no mar da Arábia, quando estava iminente um grande temporal, em que aquele capitão e muitos homens pereceram. João de Barros registou que «acodiram logo à ribeira do mar huuns poucos de mouros a que elles chamam Baduiis, cuja vida é pastorar gado e andar no campo ao modo que dizemos que andam os Alarves ${ }^{24}$.

23 Obras Completas de D. João de Castro. Coimbra, 1971. Vol. II, págs. 181-379, passim.

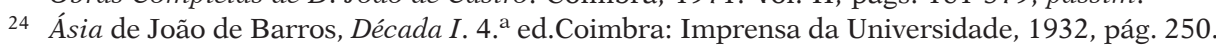

